\title{
PENGEMBANGAN ALAT UKUR KREATIVITAS VERBAL "C" (STUDI PADA MAHASISWA JURUSAN PERIKLANAN)
}

\author{
Dinah Kartana1, Joyce Natalia Setiawan², P. Tommy Y. S. Suyasa ${ }^{3}$ \\ ${ }^{1}$ Fakultas Psikologi, Universitas Tarumanagara Jakarta \\ Email: dinah.kartana@yahoo.co.id \\ ${ }^{2}$ Fakultas Psikologi, Universitas Tarumanagara Jakarta \\ Email: j.natsetiawan@gmail.com \\ ${ }^{3}$ Fakultas Psikologi, Universitas Tarumanagara Jakarta \\ Email: tommys@fpsi.untar.ac.id
}

\begin{abstract}
Creativity is a skill needed in various fields of work. Among them is the field of advertising because advertising demands the skill to create effective advertising, that is, advertisements that are different from mediocre advertisements. As a prospective professional in the field of advertising, students majoring in advertising must already possess creativity. Therefore, it is crucial to measure the creativity of students majoring in advertising before entering college. The purpose of this study is to develop a verbal creativity test tool for students majoring in advertising. Aspects of creativity measurement include fluency, flexibility, elaboration, and originality. The four aspects are measured using the "C" Verbal Creativity Test which is compiled based on the Indonesian Language Dictionary. This test is compiled using the letter $c$ as the first letter in the words used as item. The subjects of the study are 181 students of advertising major with over $2.00 \mathrm{GPA}$ who attended two universities at West Jakarta. The method of data collection involves two test kits, namely Verbal Creativity Test by Munandar and "c" Verbal Creativity Test. The result of the analysis indicates that the " $c$ " Verbal Creativity Test is declared reliable through test retest and valid by content and construct. The construction of the "c" Verbal Creativity Test resulted in percentile rank norm.
\end{abstract}

Keywords: measurement of creativity, verbal creativity test, advertising

\begin{abstract}
ABSTRAK
Kreativitas adalah kemampuan yang dibutuhkan dalam berbagai bidang pekerjaan. Salah satunya adalah bidang periklanan karena periklanan menuntut kemampuan untuk menciptakan iklan yang efektif, yaitu iklan yang berbeda dari iklan yang biasa-biasa saja. Sebagai calon tenaga profesional di bidang periklanan, mahasiswa jurusan periklanan pun sudah harus memiliki kreativitas. Oleh karena itu, sangat penting untuk mengukur kreativitas mahasiswa jurusan periklanan sebelum memasuki perguruan tinggi. Tujuan dari penelitian ini adalah untuk mengembangkan alat tes kreativitas verbal bagi mahasiswa jurusan periklanan. Aspek pengukuran kreativitas meliputi kemampuan fluency, flexibility, elaboration, dan originality, Keempat aspek tersebut diukur melalui Tes Kreativitas Verbal “c” yang disusun berdasarkan Kamus Bahasa Indonesia. Tes ini disusun dengan menggunakan huruf c sebagai huruf pertama dalam kata yang digunakan sebagai butir. Subjek penelitian berjumlah 181 mahasiswa jurusan periklanan IPK di atas 2,00 yang berkuliah di dua universitas di Jakarta Barat. Metode pengumpulan data dengan menggunakan dua buah alat tes, yaitu Tes Kreativitas Verbal oleh Munandar dan Tes Kreativitas Verbal "c". Hasil analisis menunjukkan bahwa alat Tes Kreativitas Verbal "c" dinyatakan reliable secara test retest dan valid secara content dan construct. Pada penyusunan Tes Kreativitas Verbal "c” dihasilkan norma percentile rank.
\end{abstract}

Kata kunci: pengukuran kreativitas, tes kreativitas verbal, periklanan

\section{PENDAHULUAN}

\section{Latar belakang}

Perkembangan periklanan dewasa ini semakin meningkat. Kondisi tersebut dipicu oleh media yang semakin banyak di Indonesia. Pada tahun 1997 di Indonesia terdapat 282 penerbitan. Pada akhir tahun 1999 jumlah tersebut semakin meningkat menjadi 1.675 dan pada tahun 2001 bertambah menjadi 2.033 buah. Semakin banyaknya media massa baru yang bermunculan akan 
menyebabkan munculnya kegiatan ekonomi di bidang lain. Beberapa bidang yang semakin berkembang pesat, yaitu industri kertas, percetakan, transportasi, rumah produksi, event organizer, musik, penari latar, dan periklanan (Widyatama, 2005).

Dunia periklanan sendiri menjadi pilihan kerja dengan prospek yang cerah. Negara Indonesia yang merupakan negara dengan populasi penduduk terbesar keempat di dunia merupakan pasar yang sangat potensial dan menarik bagi investor. Indonesia sangat membutuhkan tenaga-tenaga profesional dalam bidang periklanan, khususnya untuk mengantisipasi pertumbuhan bisnis yang setiap tahun berkembang. Selain itu, tenaga profesional di bidang periklanan juga dibutuhkan untuk mengantisipasi globalisasi (Gunadi dalam Tangkudung, 2007).

Sebagai tenaga profesional di bidang periklanan, kemampuan yang perlu dimiliki adalah kreativitas. Hal ini diungkapkan oleh Beauvais (2006), bahwa kreativitas merupakan salah satu kemampuan utama yang dibutuhkan dalam dunia periklanan karena dunia periklanan menuntut kemampuan untuk menciptakan iklan yang efektif.

Kreativitas adalah kemampuan untuk menghasilkan dan mengkombinasikan ide-ide, serta merupakan kemampuan untuk menciptakan sesuatu yang baru (Haefele, Seidel, Ron, \& Allen dalam Harsojo, 2004; Munandar, 1999). Kreativitas juga didefinisikan sebagai kemampuan untuk berpikir secara divergen, yang memungkinkan individu untuk menghasilkan banyak jawaban untuk satu pertanyaan (Guilford, dikutip dalam Santrock, 2012). Kreativitas berhubungan dengan kemampuan untuk mengembangkan ide-ide yang baru, menemukan ide-ide, dan menemukan alternatif atau kemungkinan untuk menyelesaikan masalah (Pratitis \& Pandin, 2002).

Dengan adanya kreativitas, maka orang-orang periklanan mampu untuk mengembangkan ide-ide dalam membuat iklan yang efektif. Iklan yang efektif adalah iklan yang kreatif, yaitu iklan yang bisa membedakan dirinya dari iklan yang biasa-biasa saja. Iklan yang kreatif adalah iklan yang tidak biasa dan berbeda. Iklan yang sama dengan sebagian besar iklan lainnya tidak akan mampu bersaing dengan iklan-iklan yang lain dan tidak dapat menarik perhatian konsumen (Smith dalam Shimp, 2000/2003).

Sebagai calon tenaga profesional di bidang periklanan, mahasiswa jurusan periklanan pun harus memiliki kreativitas (Wells et al., 1998). Kreativitas yang dibutuhkan oleh mahasiswa jurusan periklanan adalah kreativitas verbal. Hal ini dikarenakan kreativitas verbal cenderung menjadi suatu hal utama untuk menyampaikan pesan dalam sebuah iklan. Dengan adanya stimulus verbal, maka lebih memperjelas atau memudahkan konsumen untuk mengerti dan mendefinisikan suatu iklan. Oleh karena itu kreativitas verbal merupakan aspek penting dalam dunia periklanan karena pendidikan periklanan membutuhkan mahasiswa yang lebih selektif, khususnya mahasiswa yang kreatif (Schiffman \& Kanuk, 2000).

Melihat pentingnya kreativitas verbal bagi mahasiswa periklanan, maka dibutuhkan suatu pengukuran yang dapat meramalkan kreativitas verbal calon mahasiswa periklanan sebelum memasuki perguruan tinggi. Dengan pengukuran ini, dapat diungkapkan potensi-potensi kreatif dalam diri calon mahasiswa jurusan periklanan. Metode pengukuran yang dapat dilakukan adalah dengan memberikan suatu tes kreativitas (Goff, 2000; Suharnan, 2002).

Tes kreativitas merupakan suatu alat ukur yang digunakan untuk mengidentifikasi potensi kreatif individu. Aspek-aspek yang diukur pada tes kreativitas, meliputi (a) fluency, yaitu kemampuan untuk menghasilkan banyak gagasan yang relevan; (b) flexibility, yaitu kemampuan untuk 
menghasilkan gagasan yang beragam; (c) elaboration, yaitu kemampuan untuk mengembangkan gagasan; dan (d) originality, yaitu kemampuan untuk menghasilkan gagasan yang unik (Munandar, 2012)

Saat ini, salah satu alat tes kreativitas yang ada, yaitu Divergent Thinking Online Measurement Tool. Tes ini terdiri dari 9 soal yang dibuat berdasarkan tes kreativitas Torrance serta tes kreativitas Wallach dan Kogan. Dari 9 soal yang ada, 3 soal merupakan soal kegunaan alternatif (partisipan diminta menuliskan sebanyak mungkin kegunaan tidak biasa dari korek api, gelas, dan sikat gigi), 3 soal lainnya merupakan soal membuat contoh (partisipan diminta menuliskan sebanyak mungkin objek yang transparan, menghasilkan cahaya, dan bergemerincing), dan 3 soal terakhir merupakan soal mengartikan gambar. Aspek kreativitas yang diukur pada tes ini, yaitu fluency, flexibility, dan originality (Pásztor, Molnár, \& Csapó, 2015).

Untuk digunakan sebagai tes kreativitas verbal, Divergent Thinking Online Measurement Tool ini, masih bersifat terlalu umum atau universal, padahal dibutuhkan alat ukur kreativitas yang secara spesifik mampu mengukur kreativitas mahasiswa periklanan dalam berbahasa.

Beberapa contoh tes kreativitas verbal yang ada, yaitu Test of Creative Thinking Verbal (TTCTVerbal) dan Tes Kreativitas Verbal (TKV). Pertama, TTCT-Verbal. TTCT-Verbal terdiri dari enam subtes yang meliputi (a) asking questions, (b) guessing causes, (c) guessing consequences, (d) product improvement, (e) unusual uses, dan (f) just suppose. Setiap subtes mengukur aspekaspek kreativitas yang berbeda, seperti fluency, flexibility, dan originality (Gregory, 2013).

Kedua, TKV. TKV adalah alat ukur kreativitas verbal yang dikonstruksi oleh Munandar. Tes ini terdiri dari enam subtes, yang meliputi (a) permulaan kata, (b) menyusun kata, (c) membentuk kalimat tiga kata, (d) sifat-sifat yang sama, (e) macam-macam penggunaan, dan (f) apa akibatnya. Aspek kreativitas yang diukur pada tes ini adalah fluency, flexibility, originality, dan elaboration (Munandar, 1977).

Meskipun kedua alat tes tersebut dapat digunakan untuk mengukur kreativitas verbal, namun kedua alat tes tersebut memiliki keterbatasan dalam pengukuran kreativitas. Keterbatasan tersebut yaitu tercampurnya skor fluency dengan skor originality. Semakin tinggi skor fluency, semakin rendah skor originality. Oleh karena itu disarankan membuat teknik untuk melepaskan pengaruh fluency dari originality. Selain itu, disarankan juga untuk menunjukkan reliabilitas dan validitas pada hasil skor originality (Clark, Mirels, Hocevar, Runco, Albert, \& Seddon dalam Plucker \& Runco, 1998).

Kedua alat ukur tersebutpun, tidak mampu secara spesifik meramalkan kreativitas yang berhubungan dengan kemampuan mahasiswa jurusan periklanan. Padahal, alat ukur semacam ini sangat penting untuk mengidentifikasi potensi kreatif calon mahasiswa jurusan periklanan. Oleh karena itu, masih sangat perlu untuk dikembangkan alat ukur kreativitas yang dapat meramalkan kemampuan mahasiswa jurusan periklanan.

\section{Tujuan penelitian}

Untuk mengembangkan alat ukur kreativitas verbal yang dapat digunakan untuk mengukur kemampuan kreativitas mahasiswa jurusan periklanan.

\section{METODE PENELITIAN}

\section{Partisipan penelitian}


Partisipan yang dipilih dalam penelitian ini adalah mahasiswa jurusan periklanan di Universitas X dan Y. Jumlah sampel yang digunakan dalam penelitian ini adalah sebanyak 181 orang. Peneliti mengambil sampel berdasarkan latar belakang pendidikan partisipan. Selain itu, IPK sampel yang dipilih adalah minimal 2.00 karena dianggap sudah memenuhi standar untuk tidak di drop-out.

\section{Setting dan instrumen penelitian}

Penelitian ini dilakukan di ruang kelas Universitas $\mathrm{X}$ dan $\mathrm{Y}$. Instrumen penelitian yang digunakan, meliputi (a) Tes Kreativitas Verbal "c", (b) Tes Kreativitas Verbal oleh Munandar, (c) lembar jawaban, (d) stopwatch, (e) pulpen atau pensil, dan (f) souvenir.

\section{Prosedur penelitian}

Dalam penelitian ini, peneliti melakukan sepuluh tahapan, yaitu (1) studi literatur, (2) perancangan butir, (3) face validity study, (4) content validity study, (5) pengumpulan data, (6) pengujian testretest reliability, (7) scoring, (8) construct validity study, (9) criterion validity study, dan (10) pembuatan norma.

Pertama, peneliti melakukan studi literatur dengan membaca berbagai buku tentang kreativitas. Peneliti juga mempelajari terlebih dahulu metode-metode yang dilakukan dalam mengembangkan tes kreativitas.

Kedua, peneliti melakukan perancangan butir dengan menyusun 50 kata yang masing-masingnya diawali huruf $\mathrm{c}$. Penentuan huruf $\mathrm{c}$ ini dilakukan dengan metode sampling. Cara yang dilakukan adalah dengan menuliskan huruf a sampai $\mathrm{z}$ di atas kertas, menggulung kertas tersebut, memasukkannya ke dalam gelas, lalu mengocok gelas hingga keluar satu gulungan kertas. Kertas yang keluar adalah kertas yang bertuliskan huruf c. Huruf c tersebut kemudian digunakan sebagai butir dalam pembuatan tes kreativitas verbal.

Ketiga, peneliti melakukan face validity study dengan mengadakan tryout kepada 15 orang partisipan. Tryout ini diadakan untuk mengetahui apakah alat ukur tersebut dapat dipahami atau dikatakan valid secara tampilan.

Keempat, peneliti melakukan content validity study dengan meminta 5 orang pakar untuk mereview tes kreativitas yang peneliti buat. Tujuan dilakukannya content validity study ini adalah untuk mengetahui apakah butir-butir yang terdapat dalam alat ukur secara valid mampu mengukur aspek-aspek kreativitas.

Kelima, peneliti melakukan pengumpulan data. Pengumpulan data ini dilakukan terhadap mahasiswa periklanan, Fakultas Ilmu Komunikasi, Universitas X dan Universitas Y.

Keenam, peneliti melakukan pengujian test-retest reliability. Tujuan test-retest adalah untuk melihat apakah alat ukur yang dirancang sudah konsisten. Peneliti melakukan tes ulang dengan mengambil sampel 30 partisipan yang sama dengan partisipan pada pengumpulan data pertama.

Ketujuh, peneliti melakukan scoring. Untuk aspek fluency, peneliti menghitung banyaknya kalimat yang diberikan oleh partisipan berdasarkan rangsangan yang diberikan. Setiap kalimat yang dihasilkan akan diberi skor 1 . Untuk aspek flexibility, peneliti menghitung banyaknya kata yang dipakai untuk membuat kalimat. Jika partisipan menggunakan kata yang sama, baik dalam satu kalimat atau kalimat yang berbeda, maka kata tersebut tidak mendapat skor. Setiap kata yang 
digunakan untuk membuat kalimat akan diberi skor 1. Untuk aspek elaboration diperoleh dengan cara menghitung banyaknya ide-ide baru di luar kata yang menjadi stimulus. Setiap penggunaan ide baru, maka mendapatkan skor 1. Untuk aspek originality diperoleh melalui dua tahap. Tahap pertama adalah mengidentifikasi standar skor yang dimiliki oleh setiap kata. Tahap kedua adalah menjumlahkan standar skor tersebut.

Kedelapan, peneliti melakukan construct validity study. Tujuan dilakukannya construct validity study adalah untuk melihat apakah Tes Kreativitas Verbal "c" dapat merefleksikan konstruksi teoretis yang mendasari penyusunannya. Construct validity study ini dilakukan dengan mengkorelasikan skor Tes Kreativitas Verbal "c" dengan Tes Kreativitas Verbal yang dikonstruksi oleh Munandar.

Kesembilan, peneliti melakukan criterion validity study. Tujuan dilakukannya criterion validity study untuk melihat apakah hasil pengukuran Tes Kreativitas Verbal "c" dapat meramalkan prestasi belajar mahasiswa berdasarkan nilai IPK.

Kesepuluh, peneliti melakukan pembuatan norma. Pada tahap ini, peneliti membuat norma aspek fluency, flexibility, elaboration, originality, serta keseluruhan menggunakan perhitungan percentile. Tujuan pembuatan norma adalah untuk menunjukkan kedudukan atau posisi individu yang menjadi partisipan dalam populasi.

\section{HASIL DAN PEMBAHASAN}

\section{Rancangan soal tes kreativitas verbal " $c$ "}

Tes Kreativitas Verbal "c" terdiri dari (a) petunjuk pengerjaan, (b) petunjuk tambahan, dan (c) butir soal yang mencakup kata-kata yang diawali dengan huruf c. Alat tes ini hanya boleh dikerjakan saat penguji memberikan aba-aba "mulai" dan berhenti ketika penguji memberikan aba-aba "berhenti". Waktu yang dibutuhkan untuk mengerjakan Tes Kreativitas Verbal "c" adalah 10 menit.

\section{Hasil studi reliabilitas tes kreativitas verbal "c"}

Berikut ini dijelaskan lebih lanjut mengenai gambaran studi reliabilitas test-retest pada Tes Kreativitas Verbal "c" dengan selang waktu 1 minggu untuk masing-masing aspek. Gambaran hasil studi reliabilitas test-retest Tes Kreativitas Verbal "c" dapat dilihat pada Tabel 1.

Tabel 1. Gambaran hasil studi reliabilitas test-retest Tes Kreativitas Verbal "c"

\begin{tabular}{ll}
\hline Aspek & $\mathbf{r}$ \\
\hline Fluency & $0.699^{* *}$ \\
Flexibility & $0.757^{* *}$ \\
Elaboration & $0.820^{* *}$ \\
Originality & $0.986^{* *}$ \\
\hline
\end{tabular}

** korelasi dengan level signifikan 0,01 (2-tailed)

Dari tabel di atas diperoleh bahwa aspek fluency, flexibility, elaboration, dan originality memiliki reliabilitas antar waktu yang tergolong baik. Keempat aspek pengukuran tersebut memiliki konsistensi atau stabilitas skor dalam kurun waktu 1 minggu. 


\section{Hasil studi validitas tes kreativitas verbal "c"}

Pada penyusunan Tes Kreativitas Verbal "c", terdapat empat jenis validitas yang digunakan, yaitu (a) face validity, (b) content validity, (c) construct validity, dan (d) criterion validity.

\section{Hasil uji validitas tampilan (Face Validity)}

Pengujian validitas tampilan Tes Kreativitas Verbal "c" dilakukan terhadap 15 calon partisipan. Dari hasil pengujian tersebut, calon partisipan dapat memahami pengerjaan Tes Kreativitas Verbal "c". Hal tersebut dapat dilihat ketika peneliti selesai memberikan petunjuk pengerjaan, calon partisipan tidak memberikan banyak pertanyaan mengenai cara pengerjaan tes. Pada saat tes berlangsung, calon partisipan mengerjakan tes tersebut dengan baik. Ketika selesai mengerjakan tes, kalimat yang dibuat oleh calon partisipan cukup banyak dan bervariasi.

\section{Hasil uji validitas isi (Content Validity)}

Pengujian validitas isi Tes Kreativitas Verbal "c" dilakukan oleh lima orang pakar. Kelima pakar tersebut adalah (a) S.C.U.M.; (b) C.S.; (c) M.P.S.; (d) A.D.; dan (e) P.T.Y.S.S. Dari pengujian tersebut para pakar menyatakan bahwa butir-butir yang ada dalam Tes Kreativitas Verbal "c" adalah benar (dinyatakan valid) untuk mengukur aspek-aspek kreativitas.

\section{Hasil uji validitas konstruk (Construct Validity)}

Dalam penyusunan Tes Kreativitas Verbal "c", peneliti melakukan construct validity study jenis convergent validity. Dalam pengujian tersebut, peneliti melakukan uji korelasi antara hasil pengukuran Tes Kreativitas Verbal "c" dengan Tes Kreativitas Verbal oleh Munandar. Hasil pengujian dapat dilihat pada Tabel 2.

Tabel 2. Gambaran hasil studi validitas konstruk untuk setiap aspek

\begin{tabular}{lcc}
\hline Aspek & $\mathbf{r}$ & $\mathbf{p}$ \\
\hline Fluency & $0,242^{* *}$ & 0,001 \\
Flexibility & $0,362^{* *}$ & 0,000 \\
Elaboration & $0,784^{* *}$ & 0,000 \\
Originality & $0,206^{* *}$ & 0,005 \\
\hline
\end{tabular}

** korelasi dengan level signifikan 0,01 (2-tailed)

Berdasarkan tabel di atas, diketahui bahwa hasil pengukuran aspek fluency Tes Kreativitas Verbal "c" dengan aspek fluency Tes Kreativitas Verbal oleh Munandar menunjukkan adanya hubungan yang signifikan $(\mathrm{r}=0,242 ; \mathrm{p}<0,01)$. Hal ini menunjukkan bahwa semakin tinggi skor fluency Tes Kreativitas Verbal "c", maka semakin tinggi skor fluency Tes Kreativitas Verbal. Hal ini berarti Tes Kreativitas Verbal "c" mengukur aspek fluency yang diukur oleh Tes Kreativitas Verbal.

Pengukuran kedua adalah pengukuran aspek flexibility Tes Kreativitas Verbal "c" dengan aspek flexibility Tes Kreativitas Verbal oleh Munandar. Hasilnya menunjukkan bahwa terdapat hubungan yang signifikan $(\mathrm{r}=0,362 ; \mathrm{p}<0,01)$ antara aspek flexibility Tes Kreativitas Verbal "c" dengan Tes Kreativitas Verbal. Hal ini menunjukkan bahwa semakin tinggi skor flexibility Tes 
Kreativitas Verbal "c", maka semakin tinggi skor flexibility Tes Kreativitas Verbal. Hal ini berarti Tes Kreativitas Verbal "c" mengukur aspek flexibility yang diukur oleh Tes Kreativitas Verbal.

Pengukuran ketiga adalah pengukuran aspek elaboration Tes Kreativitas Verbal "c" dengan aspek elaboration Tes Kreativitas Verbal oleh Munandar. Hasilnya menunjukkan bahwa terdapat hubungan yang signifikan ( $\mathrm{r}=0,784 ; \mathrm{p}<0,01)$ antara aspek elaboration Tes Kreativitas Verbal "c" dengan Tes Kreativitas Verbal. Hal ini menunjukkan bahwa semakin tinggi skor elaboration Tes Kreativitas Verbal "c", maka semakin tinggi skor elaboration Tes Kreativitas Verbal. Hal ini berarti Tes Kreativitas Verbal "c" mengukur aspek elaboration yang diukur oleh Tes Kreativitas Verbal.

Pengukuran keempat adalah pengukuran aspek originality Tes Kreativitas Verbal "c" dengan aspek originality Tes Kreativitas Verbal oleh Munandar. Hasilnya menunjukkan bahwa terdapat hubungan yang signifikan $(\mathrm{r}=0,206 ; \mathrm{p}<0,01)$ antara aspek originality Tes Kreativitas Verbal "c" dengan Tes Kreativitas Verbal. Hal ini menunjukkan bahwa semakin tinggi skor originality Tes Kreativitas Verbal "c", maka semakin tinggi skor originality Tes Kreativitas Verbal. Hal ini berarti Tes Kreativitas Verbal "c" mengukur aspek originality yang diukur oleh Tes Kreativitas Verbal.

\section{Hasil uji validitas kriteria (Criterion Validity)}

Pada penyusunan Tes Kreativitas Verbal "c", peneliti menggunakan criterion validity study jenis predictive validity. Hal ini dilakukan dengan mengkorelasikan skor yang diperoleh dari tiap aspek dengan nilai IPK. Gambaran hasil studi validitas kriteria dapat dilihat pada Tabel 3.

Tabel 3. Gambaran hasil studi validitas kriteria (IPK sebagai kriteria)

\begin{tabular}{lcc}
\hline Aspek & r IPK-TKV"c" & p \\
\hline Fluency & 0,138 & 0,088 \\
Flexibility & 0,140 & 0,085 \\
Elaboration & 0,125 & 0,123 \\
Originality & $-0,147$ & 0,070 \\
\hline
\end{tabular}

Berdasarkan analisis aspek fluency menggunakan perhitungan korelasi Spearman Brown, diketahui bahwa aspek fluency Tes Kreativitas Verbal "c" tidak memiliki hubungan dengan IPK $(\mathrm{r}=0,138, \mathrm{p}>0,05)$. Hal ini menunjukkan bahwa semakin tinggi atau semakin rendah skor fluency Tes Kreativitas Verbal "c", belum tentu semakin tinggi atau semakin rendah skor IPK. Hal ini berarti skor aspek fluency yang diukur oleh Tes Kreativitas Verbal "c" tidak dapat meramalkan IPK.

Berdasarkan analisis aspek flexibility menggunakan perhitungan korelasi Spearman Brown, diketahui bahwa aspek flexibility Tes Kreativitas Verbal "c" tidak memiliki hubungan dengan IPK $(\mathrm{r}=0,140, \mathrm{p}>0,05)$. Hal ini menunjukkan bahwa semakin tinggi atau semakin rendah skor flexibility Tes Kreativitas Verbal "c", belum tentu semakin tinggi atau semakin rendah skor IPK. Hal ini berarti skor aspek flexibility yang diukur oleh Tes Kreativitas Verbal "c" tidak dapat meramalkan IPK.

Berdasarkan analisis aspek elaboration menggunakan perhitungan korelasi Spearman Brown, diketahui bahwa aspek elaboration Tes Kreativitas Verbal "c" tidak memiliki hubungan dengan IPK $(r=0,125, p>0,05)$. Hal ini menunjukkan bahwa semakin tinggi atau semakin rendah skor 
elaboration Tes Kreativitas Verbal "c", belum tentu semakin tinggi atau semakin rendah skor IPK. Hal ini berarti skor aspek elaboration yang diukur oleh Tes Kreativitas Verbal "c" tidak dapat meramalkan IPK.

Berdasarkan analisis aspek originality menggunakan perhitungan korelasi Spearman Brown, diketahui bahwa aspek originality Tes Kreativitas Verbal "c" tidak memiliki hubungan dengan IPK $(r=-0,147, p>0,05)$. Hal ini menunjukkan bahwa semakin tinggi skor originality Tes Kreativitas Verbal "c", belum tentu semakin rendah skor IPK. Semakin rendah skor originality Tes Kreativitas Verbal "c", belum tentu semakin tinggi skor IPK. Hal ini berarti skor aspek originality yang diukur oleh Tes Kreativitas Verbal "c" tidak dapat meramalkan IPK.

\section{Gambaran norma tes kreativitas verbal " $C$ "}

Pada gambaran norma Tes Kreativitas Verbal "c", peneliti akan membahas mengenai gambaran norma Tes Kreativitas Verbal "c". Ada lima gambaran norma yang dihasilkan, yaitu norma aspek fluency, norma aspek flexibility, norma aspek elaboration, norma aspek originality, dan norma keseluruhan aspek. Contoh gambaran norma Tes Kreativitas Verbal "c" dapat dilihat pada Tabel 4.

Tabel 4. Contoh gambaran norma Tes Kreativitas Verbal "c"

\begin{tabular}{|c|c|c|c|c|c|}
\hline \multirow{2}{*}{$\begin{array}{l}\text { Percentile } \\
\text { Score }\end{array}$} & \multicolumn{5}{|c|}{ Raw Score } \\
\hline & Fluency & Flexibility & Elaboration & Originality & Keseluruhan \\
\hline 0 & - & - & - & - & - \\
\hline 1 & 1 & 3 & - & $80-85$ & 41 \\
\hline 2 & - & - & - & $86-99$ & $42-45$ \\
\hline 3 & - & 4 & - & 100-109 & 46 \\
\hline 4 & - & 5 & 1 & $110-112$ & $47-51$ \\
\hline 5 & - & - & - & $113-114$ & 52 \\
\hline 6 & 2 & - & 2 & $115-117$ & $53-60$ \\
\hline 7 & - & 6 & - & $118-121$ & $61-68$ \\
\hline 8 & - & - & - & $122-124$ & $69-75$ \\
\hline 9 & - & - & 3 & $125-137$ & $76-79$ \\
\hline 10 & - & - & - & 138 & $80-83$ \\
\hline 11 & - & - & - & $139-144$ & 84 \\
\hline 12 & - & 7 & - & $145-146$ & $85-90$ \\
\hline 13 & - & - & - & $147-149$ & 91 \\
\hline 14 & - & - & - & $150-152$ & $92-95$ \\
\hline 15 & - & - & - & $153-155$ & 96 \\
\hline 16 & 3 & 8 & 4 & $156-157$ & $97-98$ \\
\hline 17 & - & - & - & $158-161$ & $99-102$ \\
\hline 18 & - & - & - & $162-166$ & $103-106$ \\
\hline 19 & - & - & - & $167-175$ & $107-109$ \\
\hline 20 & - & - & - & $176-184$ & $110-111$ \\
\hline 21 & - & - & 5 & 185 & 112 \\
\hline 22 & - & - & - & - & $113-117$ \\
\hline 23 & - & - & - & $186-194$ & 118 \\
\hline 24 & - & - & - & $195-202$ & $119-121$ \\
\hline 25 & - & 9 & - & 203-211 & $122-123$ \\
\hline 26 & - & - & - & 212 & $124-129$ \\
\hline 27 & - & - & 6 & 213 & 130 \\
\hline 28 & - & - & - & 214 & $131-132$ \\
\hline 29 & - & - & - & 215 & $133-134$ \\
\hline 30 & - & - & - & 216-218 & $135-140$ \\
\hline
\end{tabular}

(gambaran norma secara lengkap dapat dilihat pada dokumen peneliti) 
Norma aspek fluency diperoleh dengan menghitung total nilai aspek fluency yang dihasilkan oleh seluruh partisipan. Setelah dihitung total nilai aspek fluency, kemudian dilakukan perhitungan percentile score.

Norma aspek fluency diperoleh dengan menghitung total nilai aspek fluency yang dihasilkan oleh seluruh partisipan. Nilai aspek fluency diperoleh dengan menghitung jumlah kalimat yang dituliskan oleh partisipan sebagai jawaban atas rangsangan. Setiap kalimat yang dihasilkan akan diberi skor 1. Setelah dihitung total nilai aspekfluency, kemudian dilakukan perhitungan percentile score.

Norma aspek flexibility diperoleh dengan menghitung total nilai aspek flexibility yang dihasilkan oleh seluruh partisipan. Nilai aspek flexibility diperoleh dengan menghitung jumlah kata yang digunakan untuk membuat kalimat. Jika partisipan menggunakan kata yang sama, baik dalam satu kalimat atau kalimat yang berbeda, maka kata tersebut tidak mendapat skor. Setiap kata yang digunakan untuk membuat kalimat akan diberi skor 1. Setelah dihitung total nilai aspek flexibility, kemudian dilakukan perhitungan percentile score.

Norma aspek elaboration diperoleh dengan menghitung total nilai aspek elaboration yang dihasilkan oleh seluruh partisipan. Nilai aspek elaboration diperoleh dengan menghitung banyaknya ide-ide baru di luar kata yang menjadi rangsangan. Ide-ide tersebut terdiri dari kata imbuhan, tanda baca, huruf capital, cetak miring, cetak tebal, garis bawah, kata penghubung, kata depan, partikel, kata ganti, dan kata tidak baku. Setiap penggunaan ketentuan tersebut, maka mendapatkan skor 1. Setelah dihitung total nilai aspek elaboration, kemudian dilakukan perhitungan percentile score.

Norma aspek originality diperoleh dengan menghitung total nilai aspek originality yang dihasilkan oleh seluruh partisipan, Nilai aspek originality diperoleh melalui dua tahap. Tahap pertama adalah mengidentifikasi standar skor setiap kata. Tahap kedua adalah menjumlahkan standar skor tersebut. Setelah dihitung total nilai aspek originality, kemudian dilakukan perhitungan percentile score.

Norma keseluruhan diperoleh dengan cara menjumlahkan percentile score semua aspek yang telah dihitung. Setelah diperoleh jumlah percentile score dari keempat aspek, tahap selanjutnya adalah melakukan perhitungan percentile score dari total percentile score untuk dijadikan sebagai norma. Semakin tinggi jumlah percentile score, maka akan semakin tinggi kreativitas yang dimiliki oleh partisipan.

\section{KESIMPULAN DAN SARAN}

\section{Kesimpulan}

Peneliti menyimpulkan empat hal pada penyusunan Tes Kreativitas Verbal "c”, yaitu:

(1) Tes Kreativitas Verbal "c" terdiri dari instruksi pengerjaan dan 50 kata yang diawali dengan huruf "c" sebagai butir soal;

(2) Tes Kreativitas Verbal "c" dinyatakan memiliki test-retest reliability dalam kurun waktu 1 minggu;

(3) Tes Kreativitas Verbal "c" dapat dikatakan valid secara content, tampilan, dan construct. Namun, Tes Kreativitas Verbal "c" tidak dinyatakan valid secara criterion;

(4) Pada penyusunan Tes Kreativitas Verbal "c" dihasilkan norma percentile rank. 


\section{Saran}

Dalam penelitian ini, partisipan yang digunakan sebagai partisipan penelitian adalah mahasiswa jurusan periklanan dari dua universitas. Peneliti menyarankan agar sebaiknya partisipan yang digunakan dapat diambil dari beberapa universitas agar hasil Tes Kreativitas Verbal "c" lebih menggambarkan kreativitas mahasiswa jurusan periklanan secara umum. Peneliti juga lebih baik melakukan kontrol terhadap usia subjek dan juga IPK dari mahasiswa yang menjadi subjek. Salah satu kelemahan penelitian ini adalah adanya kemungkinan tidak semua mata kuliah mahasiswa periklanan membutuhkan kompetensi kreativitas, sehingga hal ini dapat mempengaruhi hasil penelitian.

Topik yang juga dapat dikembangkan untuk penelitian selanjutnya adalah kreativitas figural. Penelitian ini baru berfokus pada kreativitas verbal seihngga kreativitas figural pada mahasiswa periklan masih dapat dieksplorasi lebih lanjut.

Selain itu, dapat dicoba untuk melibatkan karyawan yang bergerak di bidang periklanan sebagai partisipan. Partisipan dapat diambil dari beberapa perusahaan iklan agar hasil Tes Kreativitas Verbal "c" lebih menggambarkan kreativitas karyawan yang bergerak di bidang periklanan secara umum.

Peneliti juga menyarankan agar lebih memperhatikan waktu pengerjaan alat tes. Sebaiknya dapat dibuat alat ukur kreativitas yang dapat dikerjakan dengan waktu yang lebih singkat, namun dapat mengukur aspek-aspek kreativitas. Hal ini disarankan agar penggunaan tes kreativitas lebih efektif dan efisien dalam mengukur kreativitas yang dimiliki partisipan.

\section{Ucapan Terima Kasih (Acknowledgement)}

Peneliti mengucapkan terima kasih kepada partisipan yang telah meluangkan waktunya untuk mengikuti penelitian ini. Peneliti juga mengucapkan terima kasih kepada pihak universitas yang telah mendukung penelitian ini.

\section{REFERENSI}

Beauvais, M. (2006). Creative eye. Marketing, 111, 35. Retrieved on November 10, 2006, from http://proquest.umi.com/pqdweb.html

Goff, K. (2000). Exploiting your creative resources. Journal Record, 1, 20. Retrieved on November 10, 2006, from http://proquest.um.com/pqdweb.html

Gregory, R. J. (2013). Psychological testing: History, principles, and applications ( $^{\text {th }}$ ed.). Upper Saddle River, NJ: Pearson Education.

Harsojo, G. (2004). Menjadi pribadi sangat kreatif untuk mencapai sukses. Medan: CV Eureka Sarana Sukses.

Munandar, S. C. U. (1977). Creativity and education: A study of the relationships between measures of creative thinking and a number of educational variables in Indonesian primary and junior secondary schools, Doctoral Dissertation.

Munandar, S. C. U. (1999). Kreativitas \& keterbakatan: Strategi mewujudkan potensi kreatif \& bakat. Jakarta: Gramedia.

Munandar, U. (2012). Pengembangan kreativitas anak berbakat. Jakarta: Rineka Cipta.

Pásztor, A., Molnár, G., \& Csapó, B. (2015). Technology-based assessment of creativity in educational context: the case of divergent thinking and its relation to mathematical achievement. Thinking Skills and Creativity, 28, 32-42. Retrieved from http://dx.doi.org/10.1016/j.tsc.2015.05.004 
Plucker, J. A., \& Runco, M. A. (1998). The death of creativity measurement has been greatly exaggerated: Current issues, recent advances, and future directions in creativity assessment. Roeper Review, 21, 36-40. Retrieved on November 10, 2006, from http://proquest.umi.com/pqdweb.html

Pratitis,N. T., \& Pandin, M. G. (2002). Hubungan antara karakteristik "kepribadian yang kreatif" dan motivasi ekstrinsik-intrinsik dengan kreativitas. Anima, 17, 120-130

Santrock, J. W. (2012). Educational psychology (5 ${ }^{\text {th }}$ ed.). New York, NY: Mc-Graw Hill.

Schiffman, L. G., \& Kanuk, L. L. (2000). Consumer behavior ( $7^{\text {th }}$ ed.). NJ: Prentice-Hall.

Shimp, T. A. (2003). Periklanan promosi: Aspek tambahan komunikasi pemasaran terpadi (edisi ke-5) (R. Sahrial \& D. Anikasari, Penerj.). Jakarta: Erlangga. (Buku asli diterbitkan tahun 2000).

Suharnan. (2002). Skala C. O. R. E. sebagai alternatif mengukur kreativitas: Suatu pendekatan kepribadian. Anima, 18, 36-56

Tangkudung. (2002). Gumadi sugiharso, chairman dan ceo lowe: Sukses menjual kreativitas. Retreived on Juli, 18, 2007, from http:www.sinarharapan.co.id/ce0/2002/04/1/ceo01.html

Wells, W., Burnett., \& Moriarty, S. (1998). Advertising: Principles \& practice (4 ${ }^{\text {th }}$ ed.). NJ: Prentice International.

Widyatama, R. (2005). Pengantar periklanan. Jakarta: Buana Pustaka Indonesia. 